\title{
Doxorubicin and vinorelbine act independently via p53 expression and p38 activation respectively in breast cancer cell lines
}

\author{
AA Liem', MVCL Appleyard', MA O'Neill', TR Hupp², MP Chamberlain ${ }^{3}$ and AM Thompson*,' \\ 'Department of Surgery and Molecular Oncology, University of Dundee, Dundee, UK; ${ }^{2}$ Department of Molecular and Cellular Pathology, University of \\ Dundee, Dundee, UK; ${ }^{3}$ Biomedical Research Centre, University of Dundee, Dundee, UK
}

\begin{abstract}
In the treatment of breast cancer, combination chemotherapy is used to overcome drug resistance. Combining doxorubicin and vinorelbine in the treatment of patients with metastatic breast cancer has shown high response rates; even single-agent vinorelbine in patients previously exposed to anthracyclines results in significant remission. Alterations in protein kinase-mediated signal transduction and p53 mutations may play a role in drug resistance with cross-talk between signal transduction and p53 pathways. The aim of this study was to establish the effects of doxorubicin and vinorelbine, as single agents, in combination, and as sequential treatments, on signal transduction and p53 in the breast cancer cell lines MCF-7 and MDA-MB-468. In both cell lines, increased p38 activity was demonstrated following vinorelbine but not doxorubicin treatment, whether vinorelbine was given prior to or simultaneously with doxorubicin. Mitogen-activated protein kinase (MAPK) activity and p53 expression remained unchanged following vinorelbine treatment. Doxorubicin treatment resulted in increased p53 expression, without changes in MAPK or p38 activity. These findings suggest that the effect of doxorubicin and vinorelbine used in combination may be achieved at least in part through distinct mechanisms. This additivism, where doxorubicin acts via p53 expression and vinorelbine through p38 activation, may contribute to the high clinical response rate when the two drugs are used together in the treatment of breast cancer.

British Journal of Cancer (2003) 88, I28I-1284. doi:I0.1038/sj.bjc.6600898 www.bjcancer.com

(C) 2003 Cancer Research UK
\end{abstract}

Keywords: doxorubicin; vinorelbine; signal transduction; p53; additivism

Anthracyclines are one of the most active agents in primary adjuvant and palliative treatment of breast cancer (Kroger et al, 1999). In metastatic breast cancer, response rates to single doxorubicin treatment range from $52 \%$ in previously untreated patients to $28 \%$ in patients previously exposed to an alkylating agent (Perry, 1996; Esteva et al, 2001). Vinorelbine single-agent treatment of metastatic breast cancer achieves response rates of $35-45 \%$ as first-line and $15-30 \%$ as second-line therapy (Fumoleau et al, 1995; Burstein et al, 2001). Despite prior exposure to anthracycline therapy, patient remission was obtained in up to $47 \%$ using vinorelbine as a single agent, and for anthracycline-resistant cancers a response rate of $16 \%$ was still achieved (Kroger et al, 1999). However, the development of drug resistance in cancer cells, particularly against single agents, results in incomplete responses to chemotherapy (Jensen et al, 1999; Coley et al, 2000; Stavrovskaya, 2000). Combined vinorelbine and doxorubicin treatment for metastatic breast cancer has shown higher (74\%) overall response rates compared to single-agent treatment (Tsuruo et al, 1994; Fumoleau et al, 1995; ESMO, 2000), suggesting a synergistic effect of the two drugs.

\footnotetext{
*Correspondence: Professor AM Thompson, Department of Surgery and Molecular Oncology, Ninewells Hospital and Medical School, Dundee DDI 9SY, UK; E-mail: a.m.thompson@dundee.ac.uk

Received 29 August 2002; revised II December 2002; accepted 30 January 2003
}

A detailed knowledge of the mechanisms of action of chemotherapy agents such as doxorubicin and vinorelbine remains incomplete. Two possible routes include signal transduction pathways and the p53 pathway.

Signal transduction is involved in coordinating the cellular response to environmental stresses and is one of the fundamental processes of living cells (Dhanasekaran, 1998; Davis, 2000; Jordan et al, 2000; Liem et al, 2002). Through these pericellular communications, embryological cells grow, migrate and differentiate, and adult cells maintain their cellular integrity through cell proliferation (cell cycle progression) or cell death (apoptosis) in response to external stimuli (Pawson, 1995; Wang et al, 1998; Maemura et al, 1999).

Within the mitogen-activated protein kinase (MAPK) family, function of the extracellular signal regulated kinase (ERK, here referred to as MAPK) and p38 appear to be coordinated with JNK in mammary epithelial cells (Agarwal et al, 2000; Finlay et al, 2000).

p53 is a key gene involved in tumour response to therapy, integrating cellular stress including the action of chemotherapy agents resulting in a range of responses including cell cycle arrest and apoptosis (Hupp et al, 2000; Vogelstein et al, 2000; Ziyaie et al, 2000).

In drug resistance, cross-talk between alterations in signal transduction pathways and the p53 gene has been suggested (Agarwal et al, 2001). To identify whether either of these pathways might be relevant in the treatment of breast cancer, this study was performed to establish the effect of doxorubicin and vinorelbine on signal transduction and p53 expression. 


\section{MATERIALS AND METHODS}

\section{Cell culture}

MDA-MB-468 and MCF-7 human breast cancer cell lines were obtained from the American Type Culture Collection and cultured in $5 \% \mathrm{CO}_{2}$ at $37^{\circ} \mathrm{C}$ using Dulbecco's modified Eagle's medium, supplemented with $10 \%$ fetal bovine serum and $1 \%$ penicillin/ streptomycin. All experiments were performed in triplicate.

\section{Treatments}

MTT cytotoxicity assays (Table 1 ) were performed for doxorubicin and vinorelbine. Using the $\mathrm{IC}_{50}$ value for vinorelbine and doxorubicin, MDA-MB-468 and MCF-7 were treated for a total of $4 \mathrm{~h}$. While maintaining the vinorelbine treatment for $3 \mathrm{~h}$, doxorubicin was added either $1 \mathrm{~h}$ before (pretreatment with doxorubicin), $1 \mathrm{~h}$ after (pretreatment with vinorelbine), or at the same time (combined treatment). Single-agent controls were set up in parallel with preand combined treatment regimes. Mitogen-activated protein kinase and p38 activities were determined by kinase assay for the appropriate substrate. p53 expression was determined by Western blotting following treatment for 4 and $24 \mathrm{~h}$ with both drugs using $\mathrm{IC}_{30}$ values as single agent or in combination.

Table I Treatment regimens

\begin{tabular}{cccccc}
\hline \multicolumn{3}{c}{ MCF-7 breast cancer cells } & & MDA-MB 468 breast cancer cells \\
\cline { 2 - 3 } \cline { 5 - 6 } & Doxorubicin & Vinorelbine & & Doxorubicin & Vinorelbine \\
\hline $\mathrm{IC}_{50}$ & $10 \mu \mathrm{M}$ & $40 \mu \mathrm{M}$ & & $100 \mathrm{nM}$ & $30 \mu \mathrm{M}$ \\
$\mathrm{IC}_{30}$ & $50 \mathrm{nM}$ & $5 \mathrm{nM}$ & & - & - \\
\hline
\end{tabular}

\section{Mitogen-activated protein kinase and p38 immunoprecipitation}

Following treatment, cells were washed in ice-cold PBS and harvested by mechanical dislodging using a disposable cell scraper (Sarstedt Inc.) in the presence of cell lysis buffer (NEBS), supplemented with phenylmethylsulfonylfluoride for $5 \mathrm{~min}$. The cell lysates were sonicated on ice (Soniprep 150, Sanyo) at full amplitude for four $5 \mathrm{~s}$ bursts and centrifuged at 13000 r.p.m. for $10 \mathrm{~min}$ at $4{ }^{\circ} \mathrm{C}$. Protein levels were determined spectrophotometrically within the supernatants and $200 \mu \mathrm{l}$ cell lysates (containing $200 \mu \mathrm{g}$ total protein) were incubated overnight at $4^{\circ} \mathrm{C}$ with $15 \mu \mathrm{l}$ of immobilised phospho-p44/42 MAPK monoclonal antibody or $20 \mu \mathrm{l}$ of immobilised phospho-p38 MAPK monoclonal antibody for the MAPK and p38 assay, respectively.

\section{Protein kinase assays and Western blot analysis}

Following incubation, the suspensions were microcentrifuged at 13000 r.p.m. at $4{ }^{\circ} \mathrm{C}$ for $10 \mathrm{~min}$ and washed in $500 \mu \mathrm{l}$ of $1 \times$ lysis buffer and $500 \mu \mathrm{l}$ of $1 \times$ kinase buffer. Pellets were suspended in $50 \mu \mathrm{l}$ of $1 \times$ kinase buffer supplemented with $200 \mu \mathrm{M}$ ATP and $2 \mu \mathrm{g}$ of ELK-1 or ATF-2 fusion protein for the MAPK and p38 assays, respectively. Incubation was performed at $30^{\circ} \mathrm{C}$ for $30 \mathrm{~min}$ at 1250 r.p.m. and reactions were terminated with $25 \mu \mathrm{l}$ of $3 \times$ SDS sample buffer. Samples were boiled at $100^{\circ} \mathrm{C}$ for $5 \mathrm{~min}$, centrifuged at 10000 r.p.m., $30 \mu \mathrm{l}$ was loaded onto a $4-12 \%$ Bis-tris (Novex) gels in MOPS running buffer, transferred to a nitrocellulose membrane (Nupage running buffer) and probed with PhosphoELK-1 or Phospho-ATF-2 primary antibody $(1: 1000)$ for MAPK and $\mathrm{p} 38$, respectively. Visualisation with LumoGlo chemiluminescent reagent was performed following $1 \mathrm{~h}$ incubation in $10 \mathrm{ml}$
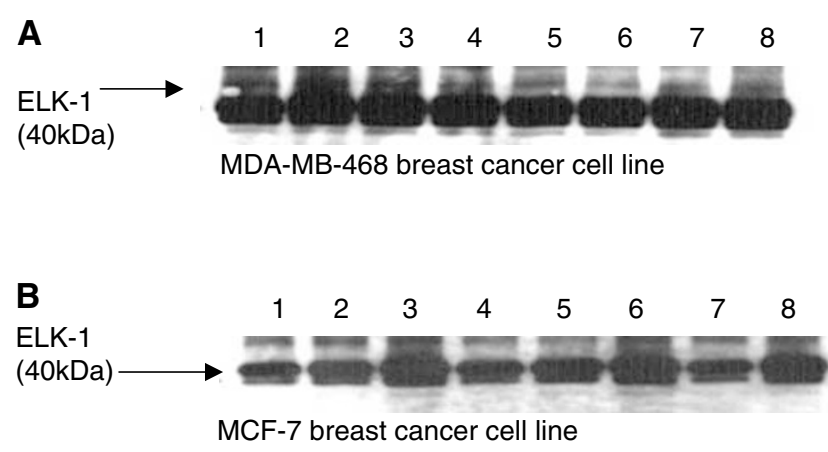

\begin{tabular}{|ll|}
\hline 1. Untreated & 5. Vinorelbine $3 \mathrm{~h}$ \\
2. Doxorubicin $4 \mathrm{~h}$ & 6. Doxorubicin and vinorelbine \\
3. Pretreatment with doxorubicin & 7. Doxorubicin $2 \mathrm{~h}$ \\
4. Doxorubicin $3 \mathrm{~h}$ & 8. Pretreatment with vinorelbine \\
\hline
\end{tabular}

Figure I Western blot showing MAPK activity in MDA-MB-468 (A) and MCF-7 (B) breast cancer cell lines treated with doxorubicin $\left(\mathrm{IC}_{50}\right)$ and vinorelbine $\left(\mathrm{IC}_{50}\right)$ at different time points. Lane I shows untreated cells (control); lanes 2 and 3 represent doxorubicin control (4h) and pretreatment with doxorubicin followed by vinorelbine; Lanes 4 and 5 show doxorubicin and vinorelbine control for the combined doxorubicin and vinorelbine treatment which is shown in lane 6; lanes 7 and 8 show doxorubicin control and vinorelbine pretreatment respectively. The MAPK activity was determined as previously described.

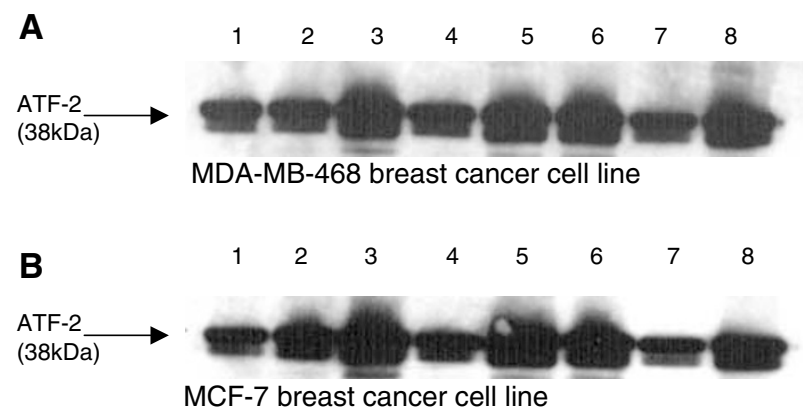
1. Untreated
5. Vinorelbine $3 \mathrm{~h}$
2. Doxorubicin $4 \mathrm{~h}$
6. Doxorubicin and vinorelbine
3. Pretreatment with doxorubicin
4. Doxorubicin $3 \mathrm{~h}$
7. Doxorubicin $2 \mathrm{~h}$
8. Pretreatment with vinorelbine

Figure 2 Western blot showing p38 activity in MDA-MB-468 (A) and MCF-7 (B) breast cancer cell lines treated with doxorubicin $\left(\mathrm{IC}_{50}\right)$ and vinorelbine $\left(\mathrm{IC}_{50}\right)$ at different time points. Lane I shows untreated cells (control); lanes 2 and 3 represent doxorubicin control (4h) and pretreatment with doxorubicin followed by vinorelbine; Lanes 4 and 5 show doxorubicin and vinorelbine control for the combined doxorubicin and vinorelbine treatment which is shown in lane 6; lanes 7 and 8 shows doxorubicin control and vinorelbine pretreatment, respectively. The p38 activity was determined as previously described.

blocking buffer supplemented with horseradish peroxidase-conjugated anti-rabbit antibody $(1: 2000)$.

\section{p53 assay}

Treated cells were harvested in $1 \mathrm{ml}$ PBS, centrifuged and supernatants were resuspended in $250 \mu$ l urea lysis buffer for $30 \mathrm{~min}$ on ice. Protein concentration was determined and $20 \mu \mathrm{g}$ protein was separated and transferred as described above, incubated for $1 \mathrm{~h}$ in CM 1 primary antibody $(1: 1000)$ and detected using chemiluminescence. 
A

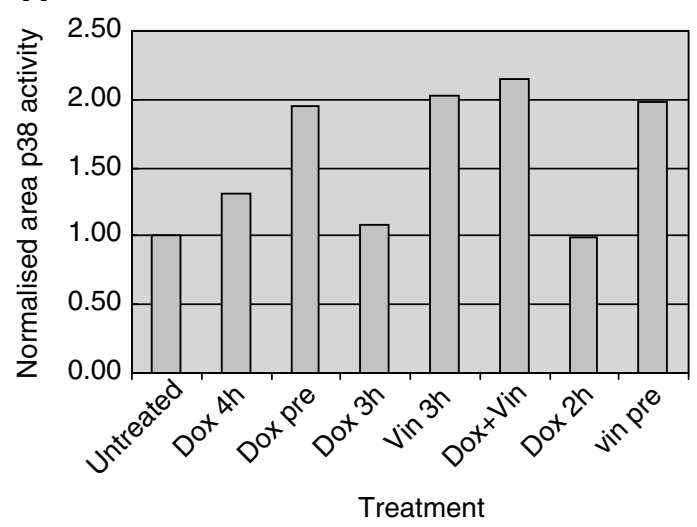

B

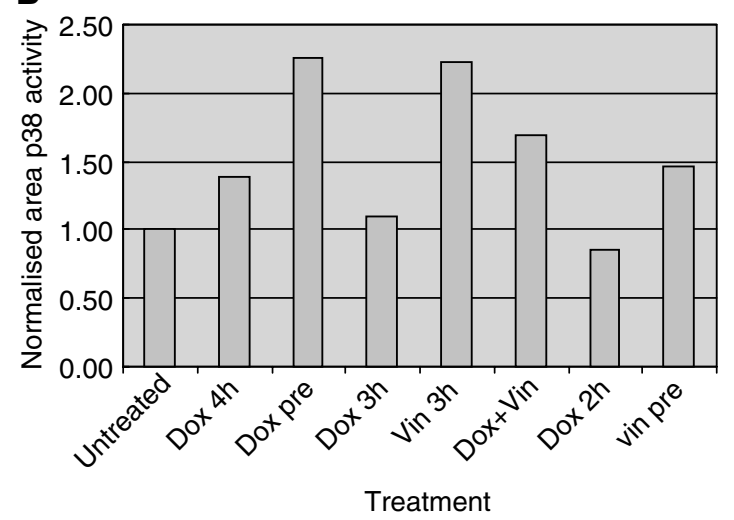

Figure 3 Quantification of p38 activity in MDA-MB-468 (A) and MCF-7 (B) breast cancer cell lines determined via densitometry following treatment with doxorubicin $\left(I C_{50}\right)$ and vinorelbine $\left(I C_{50}\right)$. The $y$-axis represents the fold increase of normalised area of p38 activity. The $x$-axis displays the untreated cells (lane I); doxorubicin control (4h) and doxorubicin pre treatment followed by vinorelbine (lanes 2 and 3 ); the $3 \mathrm{~h}$ doxorubicin and vinorelbine treatment (lanes 4 and 5) and combined doxorubicin and vinorelbine treatment (lane 6); doxorubicin $(2 \mathrm{~h})$ and vinorelbine pretreatment follwed by doxorubicin is shown in lanes 7 and 8 .

\section{Densitometry}

Protein activity was quantified by scanning the films using densitometry (Molecular Analyst). The activity was plotted as a function of the fold increase of normalised area of kinase activity.

\section{RESULTS}

The MDA-MB-468 and MCF-7 breast cancer cell lines showed constitutive MAPK and p38 activation (Figures 1 and 2). Doxorubicin treatment did not affect MAPK nor p38 activity and vinorelbine did not significantly affect MAPK activity.

However, vinorelbine elicited increased p38 activity (Figure 2, lanes $3,5,6,8)$. This occurred when vinorelbine was administered as a single agent (Figure 2, lane 5), as pretreatment followed by doxorubicin (Figure 2, lane 8) or given simultaneously with doxorubicin (Figure 2, lane 6). Similar effects were demonstrated when doxorubicin was administered prior to vinorelbine (Figure 2, lane 3). Quantification of p38 activity using densitometry (Figure 3) showed a two-fold increase of normalised area of p38 activity in vinorelbine-treated MDA-MB-468 and MCF-7 cells compared to the nonvinorelbine-treated cells (Figure 3, lanes 3, 5, 6, 8).

For p53 expression detected by the CM-1 antibody in the MCF-7 breast cancer cell line (Figure 4, lanes 3, 5, 7, 9), p53

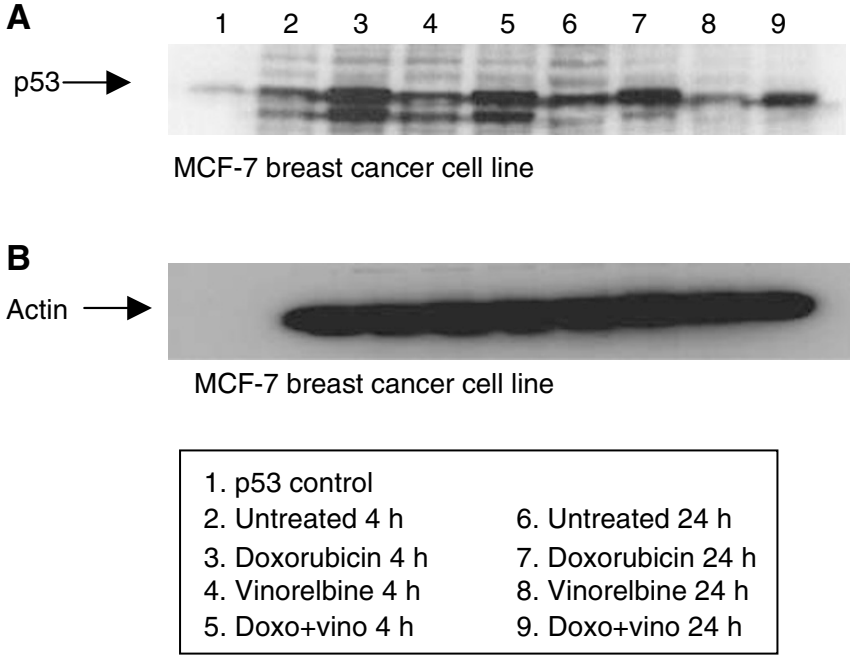

Figure 4 Western blot showing changes in p53 expression in MCF-7 breast cancer cell line following doxorubicin $\left(\mathrm{IC}_{30}\right)$ and vinorelbine $\left(\mathrm{IC}_{30}\right)$ treatment at 4 and $24 \mathrm{~h}(\mathbf{A})$. A measure of $20 \mu \mathrm{g}$ protein was loaded. Lane I represents p53 control Sf 9 cells. Lanes 2 and 6 show the untreated cells for 4 and $24 \mathrm{~h}$ respectively. Single doxorubicin or vinorelbine treatment for 4 and $24 \mathrm{~h}$ displayed in lanes 3, 4, 7 and 8 , is respectively, and combined treatment for 4 and $24 \mathrm{~h}$ shown in lanes 5 and 9 . Following treatment, cells were lysed, protein concentration was determined and p53 expression was visualised using Western blotting. Membranes were probed using CM-I antibody. Probing for actin showed equal loading (B).

induction was noted following doxorubicin but not vinorelbine treatment.

\section{DISCUSSION}

This study examined the effect of doxorubicin and vinorelbine in vitro on the MAPK family and p53 pathways using two breast cancer cell lines. The two drugs principally act via different mechanisms: doxorubicin intercalates among DNA base pairs resulting in conformational changes in DNA structure and changes in the activity of topoisomerases, whereas vinorelbine is known to disrupt microtubules in the mitotic spindle formation, inducing metaphase arrest during mitosis (Perry, 1996). Constitutive MAPK and p38 activity was confirmed in the MDA-MB-468 and MCF-7 breast cancer cell lines (Sivaraman et al, 1997; Hoshino et al, 1999). However, when vinorelbine was administered, increased p38 activity was shown in both cell lines. Whether this was because of increased gene expression, increased translation or post-translational modification is unclear. This effect was not seen with doxorubicin, which appeared not to interfere with the p38 activity of vinorelbine. Under the same growth conditions, increased p53 expression, but not enhanced p38 activity, was demonstrated in MCF-7 when treated with doxorubicin, confirming a p53-mediated response to doxorubicin in cells containing a wild-type p53 gene product (Bowcock, 1999; Roses, 1999; Perego et al, 2001). While it has been suggested that cross-talk may occur between p38 and p53 (Sanchez-Prieto et al, 2000), the current data favour independent activity of p38 and p53 (Bacus et al, 2001). These in vitro findings provide a molecular basis for the clinical response shown in patients treated with doxorubicin and vinorelbine given in combination. Additivism, where doxorubicin exerts its activity through the p53 pathway and vinorelbine through the MAPK (p38) pathway may account, at least in part, for the high clinical response rate. 


\section{ACKNOWLEDGEMENTS}

We thank Professor CR Wolf for his constructive comments. This work was supported by Breast Cancer Research

\section{REFERENCES}

Agarwal C, Sharma Y, Zhao J, Agarwal R (2000) A polyphenolic fraction from grape seeds causes irreversible growth inhibition of breast carcinoma MDA-MB468 cells by inhibiting mitogen-activated protein kinases activation and inducing G1 arrest and differentiation. Clin Cancer Res 6: $2921-2930$

Agarwal ML, Ramana CV, Hamilton M, Taylor WR, DePrimo SE, Bean LJ, Agarwal A, Agarwal MK, Wolfman A, Stark GR (2001) Regulation of p53 expression by the RAS-MAP kinase pathway. Oncogene 20: $2527-2536$

Bacus SS, Gudkov AV, Lowe M, Lyass L, Yung Y, Komarov AP, Keyomarsi K, Yarden Y, Seger R (2001) Taxol-induced apoptosis depends on MAP kinase pathways (ERK and p38) and is independent of p53. Oncogene 20: $147-155$

Bowcock A (1999) Breast Cancer. Molecular Genetics, Pathogenesis, and Therapeutics. New Jersey: Humana Press.

Burstein HJ, Bunnell CA, Winer EP (2001) New cytotoxic agents and schedules for advanced breast cancer. Semin Oncol 28: $344-358$

Coley HM, Verrill MW, Gregson SE, Odell DE, Fisher C, Judson IR (2000) Incidence of P-glycoprotein overexpression and multidrug resistance (MDR) reversal in adult soft tissue sarcoma. Eur J Cancer 36: 881-888

Davis RJ (2000) Signal transduction by the JNK group of MAP kinases. Cell 103: $239-252$

Dhanasekaran N (1998) Cell signaling: an overview. Oncogene 17: 1329 1330

ESMO A (2000) 25th European Society of Medical Oncology (ESMO) Congress. Hamburg, Germany, 13-17 October 2000. Abstracts. Ann Oncol 11: $1-193$

Esteva FJ, Valero V, Pusztai L, Boehnke-Michaud L, Buzdar AU, Hortobagyi GN (2001) Chemotherapy of metastatic breast cancer: what to expect in 2001 and beyond. Oncologist 6: $133-146$

Finlay D, Healy V, Furlong F, O'Connell FC, Keon NK, Martin F (2000) MAP kinase pathway signalling is essential for extracellular matrix determined mammary epithelial cell survival. Cell Death Differ 7: $302-$ 313

Fumoleau P, Delozier T, Extra JM, Canobbio L, Delgado FM, Hurteloup P (1995) Vinorelbine (Navelbine) in the treatment of breast cancer: the European experience. Semin Oncol 22: 22-28; discussion 28-9

Hoshino R, Chatani Y, Yamori T, Tsuruo T, Oka H, Yoshida O, Shimada Y, Ari-i S, Wada H, Fujimoto J, Kohno M (1999) Constitutive activation of the $41-/ 43-\mathrm{kDa}$ mitogen-activated protein kinase signaling pathway in human tumors. Oncogene 18: $813-822$

Hupp TR, Lane DP, Ball KL (2000) Strategies for manipulating the p53 pathway in the treatment of human cancer. Biochem J 352: 1-17
Scotland including the Breast Cancer Research Scotland Fellowship to AAL.
Jensen PB, Sehested M, Langer SW, Hansen HH (1999) Twenty-five years of chemotherapy in small cell lung cancer sends us back to the laboratory. Cancer Treat Rev 25, 377-386

Jordan JD, Landau EM, Iyengar R (2000) Signaling networks: the origins of cellular multitasking. Cell 103: $193-200$

Kroger N, Achterrath W, Hegewisch-Becker S, Mross K, Zander AR (1999) Current options in treatment of anthracycline-resistant breast cancer. Cancer Treat Rev 25: 279-291

Liem A, Chamberlain M, Wolf C, Thompson A (2002) Review: the role of signal transduction in anti-cancer drug resistance. Eur J Surg Onco 28: $679-684$

Maemura M, Iino Y, Koibuchi Y, Yokoe T, Morishita Y (1999) Mitogenactivated protein kinase cascade in breast cancer. Oncology 57: $37-44$

Pawson T (1995) Protein modules and signalling networks. Nature 373: $573-580$

Perego P, Corna E, De Cesare M, Gatti L, Polizzi D, Pratesi G, Supino R, Zunino F (2001) Role of apoptosis and apoptosis-related genes in cellular response and antitumor efficacy of anthracyclines. Curr Med Chem 8: $31-37$

Perry M (1996) The Chemotherapy Source Book. Baltimore: Williams \& Wilkins

Roses D (1999) Breast Cancer. Vol. 1. New York: Churchill Livingstone

Sanchez-Prieto R, Rojas JM, Taya Y, Gutkind JS (2000) A role for the p38 mitogen-acitvated protein kinase pathway in the transcriptional activation of p53 on genotoxic stress by chemotherapeutic agents. Cancer Res 60: $2464-2472$

Sivaraman VS, Wang H, Nuovo GJ, Malbon CC (1997) Hyperexpression of mitogen-activated protein kinase in human breast cancer. J Clin Invest 99: $1478-1483$

Stavrovskaya AA (2000) Cellular mechanisms of multidrug resistance of tumor cells. Biochemistry (Moscow) 65: 95-106

Tsuruo T, Inaba M, Tashiro T, Yamori T, Ohnishi Y, Ashizawa T, Sakai T, Kobayashi S, Gomi K (1994) Evaluation of antitumor activity of navelbine (vinorelbine ditartrate) against human breast carcinoma xenografts based on its pharmacokinetics in nude mice. Anticancer Drugs 5: $634-640$

Vogelstein B, Lane D, Levine AJ (2000) Surfing the p53 network. Nature 408: $307-310$

Wang X, Martindale JL, Liu Y, Holbrook NJ (1998) The cellular response to oxidative stress: influences of mitogen-activated protein kinase signalling pathways on cell survival. Biochem J 333: 291 - 300

Ziyaie D, Hupp TR, Thompson AM (2000) p53 and breast cancer. Breast 9: $239-246$ 